We do endeavour always to send letters of thanks to all concerned. The efficacy of transplantation for all organs is widely reported in the medical press and we lecture frequently and regularly on all aspects of transplantation, includ ing the mangement of organ donors, thoughou Britain. We would be only too happy to lecture in $\mathrm{Mr}$ Richard's unit. As far as the general media are concerned it is important to remember that transplantation is unique in medical practice in that organs are donated from the general public at a time of acute personal distress in order to help an anonymous recipient. Unlike the medical profession, the only way the public can see the results, problems, and benefits that can arise from transplant activity is through responsible media coverage.

We endeavour always to fit in with the plans and timings set by referring hospitals in conjunction with the other transplant teams but consider statements such as the one made by Mr Richard that "he" specifies a time by which the procedure must be completed, and if the transplant team cannot fall in with that time then they will miss ou on the organ, are selfish. All concerned in transplantation should realise that this attitude does not deny the transplant surgeon an organ but a potential recipient the opportunity to receive an organ and to improve their quality and quantity of life.

The heart must function immediately on im plantation, and current preservation techniques provide a maximum ischaemic period of about fou hours. The time taken in the organ procurement procedure therefore determines the time in which the implantation must be performed. Not only do arrangements have to be made for the procuremen procedure but also the recipient must be transported to the transplant centre, often from long distances such as Scotland and Northern Ireland, and be prepared for surgery so that the heart can be transplanted immediately on its arrival.

When appropriate we would welcome early referral of potential donors after initial tests have confirmed the absence of brain stem function. This would help both ourselves and the donor hospitals with their plans, and we ask that referring hospital do not make unreasonable demands on the transplant centres so that this scarce resource can be used to maximum benefit.

J WALLWORK J HUTTER

T A H ENGLISH

Papworth Hospital,

Cambridge CB3 8RE

SIR,-As transplant coordinators we agree with Mr P Richards that it is wrong and counter productive to continually blame intensive care unit staff for the lack of donor referrals (27 February, $p$ 642). The BBC That's Life programme on transplants on 10 January 1988 failed to emphasise the difficulties intensive care units are facing with closed beds and staff shortages and also that brain death is an infrequent event in many district general hospitals.

Little coverage has been given to the role of the coordinator in Britain. Most of us provide support and practical help throughout the donor referral process to the relatives and staff. A letter of appreciation is always sent to relatives and the staff concerned. Many relatives continue to keep in touch with us long after donation. When consen has been given to organ donation it is our responsibility to carry out the wish of the patient and relatives, ensuring that organs are used. It is not our experience that the procedure is delayed through transplant teams, but it is frequently delayed through lack of available theatre facilities.

New guidelines on care and related issues have been issued nationally by the Transplant Coordinators Association. They should be available in all intensive care units. Our job is very active and we are therefore unable to agree with many of Mr Richards's comments

Alison Crombie

Charing Cross Hospital (Fulham), JOANNA NiCHOLLS

London W6 8RF

\section{Do psychiatric registrars take a proper drinking history?}

SIR,-Drs M P Farrel and A S David report deficiencies in drinking histories taken by psychiatric registrars working at the Maudsley Hospital (6 February, p 395). In a recent retrospective audit of an acute (disturbed) admission ward in a teaching hospital the findings were similar. The case notes of 30 patients admitted consecutively to the ward were scrutinised. These notes contained full records of 60 admissions, which had been clerked by seven psychiatric trainees. In seven cases there was no mention of drinking history, in 12 a qualitative account was recorded, and in 11 quantitative information was obtained.

The explanation for these findings may be of interest. Nineteen of the 30 patients had detailed and comprehensive histories; of the remainder, nine had severe functional psychoses, one was mentally handicapped, and one had a dementing illness (previously diagnosed in another hospital as Huntington's chorea). During these admissions it was very difficult to obtain histories of adequate detail from the patient; accounts from other people were limited or absent. Two of the functionally psychotic patients were transferred to other hospitals and may have been more competent at a later stage; two discharged themselves from hospital.

We agree that a history of alcohol intake is essential as part of the routine assessment of psychiatric inpatients. These data, however, suggest that this may sometimes be difficult to obtain. Trainees should be encouraged to return to this subject later in the admission; full histories from relatives and friends are often crucial, although in shifting inner city populations they are not always available. In a small number of the most disabled patients it may never be possible to achieve an adequate history.

\section{Rosalyn Coleman}

Academic Department of Psychiatry STUART TURNER

Middlesex Hospital Medical School

and University College London,

condon WCIE 6JJ

\section{Acheson: a missed opportunity for the new} public health

SIR, - The Acheson committee had as its focus the future development of the public health function. Its specific remit concerned the specialty of community medicine but also the need for improvements in effectiveness and efficiency. ${ }^{1}$ This included the best use of existing resources, and $\mathrm{Dr}$ John Ashton (23 January, p 231) has correctly criticised the report for not allying community medicine with those engaged in promoting public health outside the NHS. It is also a matter for regret that groups within the NHS have been left out of the committee's plans_-notably community paediatric doctors

Child health doctors are substantial in number (community health service medical staff, most of whom are engaged in child health, take up 2347 whole time equivalents compared with 779 for community medicine ${ }^{2}$ ). They are an increasingly effective group representing a powerful blend of experience and enthusiasm-more mature doctors combining with an infusion of younger paediatricians. Training schemes are increasing ${ }^{3}$ and both older and younger doctors are moving into consultant community paediatric posts.

Community paediatrics deals with many aspects of public health relating to children-immunisation, developmental surveillance, and health education in clinics and schools. Unless this contribution is taken into account confusion will arise at district level. Does the chairman of a local authority education committee turn to the director of public health or to the consultant community paediatrician responsible for the school health service? Similarly, who should a social services chairman contact over child abuse? Particular problems will arise over immunisation and in fectious disease. Individual community paediatricians are responsible for immunisation in some districts. Would the proposed control of infection officers take over their role? When a serious infection occurs in a nursery or school will the attached child health doctor be involved or not? Since so many outbreaks of infectious disease affect children it would seem sensible to have a community paediatrician as well as a general practitioner on a district control of infection committee.

Regrettably, the contribution of community paediatricians to the public health is not considered in the Acheson report. Powerful teamwork is possible if the proposed public health specialists are made aware of the legitimate contribution of their community paediatric colleagues. If not, the present confusion over who is responsible for child health in the community will only worsen.

\section{ANGUS NicolL}

Department of Tropical Hygiene,

London School of Hygiene and Tropical Medicine,

London WC1E 7HT

1 Committee of Inquiry into the Future Development of the Public Health Function. Public health in England. London HMSO, 1988. (Acheson report.)

2 Statistics and Research Division, Department of Health and Social Security. Community medicine and community service medical staff England and Wales. Regional tables. London: DHSS, 1987.

3 Colver AF, Danskin MJ, Arkin JM, et al. Training programme for senior registrars in community paediatrics. Arch Dis Child 1988;63:63-5

SIR,-Dr John Ashton (23 January, p 231) was critical of the Acheson inquiry but I believe that its recommendations would go far in improving the organisation and morale of those working in public health medicine. With concern increasing about the performance of the National Health Service the recommendations should be quickly implemented.

The report emphasises the importance of health services research. One of the greatest disappointments since the development of community medicine in 1974 has been the limited amount of health services research undertaken. Reductions in staff funded by the University Grants Committee in some academic departments are another reason for lack of progress. Some difficulties in health service research are outlined in the report, but para 8.22 , which criticises the quality of applications, could be misleading. The practical nature and time scale of health service research requirements are different from those of other epidemiological research. Close collaboration and agreement with other health professionals are needed, and appropriate timing is all important. Opportunities often arise at short notice and advance planning is often difficult. For this reason the usual methods of seeking research funds are sometimes inappropriate. Reviewing the literature and writing a scientific 